\title{
Endothelin B receptors exert antipruritic effects via peripheral $\kappa$-opioid receptors
}

\author{
WENJIN JI ${ }^{1,3}$, JIEXIAN LIANG ${ }^{1}$ and ZHIWEI ZHANG ${ }^{2}$ \\ Departments of ${ }^{1}$ Anesthesiology, and ${ }^{2}$ Pediatric Cardiology, Guangdong Cardiovascular Institute, \\ Guangdong General Hospital, Guangdong Academy of Medical Sciences; ${ }^{3}$ Postgraduate Institute, \\ Southern Medical University, Guangzhou, P.R. China
}

Received April 2, 2012; Accepted June 20, 2012

DOI: $10.3892 /$ etm.2012.624

\begin{abstract}
Endothelin B receptor agonists exert antipruritic effects on itching induced via endothelin-1 (ET-1) and compound 48/80. Peripheral $\mu$ - and $\kappa$-opioid receptors (MORs and KORs, respectively) are reported to be involved in the antinociceptive properties triggered by $\mathrm{ET}_{\mathrm{B}}$ agonists. Therefore, we investigated the role of peripheral opioid receptors in the scratching response induced by ET-1. $\mathrm{ET}_{\mathrm{A}}$ and $\mathrm{ET}_{\mathrm{B}}$ antagonists and non-selective and selective opioid receptor antagonists were co-injected with ET-1 in the neck of mice and the number of scratching bouts was counted. Pretreatment with systemically administered naloxone significantly reduced the number of scratches, while co-injection of naloxone substantially augmented the effect of ET-1. Co-injection of nor-Binaltorphimine (nor-BNI), a KOR antagonist, significantly increased the number of scratches induced by ET-1. However, CTOP (a MOR antagonist) and naltrindole [a $\delta$-opioid receptor (DOR) antagonist] did not alter the scratching response elicited by ET-1. These results indicate that peripheral KORs mediate the antipruritic effect of endothelin B receptor activation.
\end{abstract}

\section{Introduction}

Endothelin-1 (ET-1) is generated by a variety of cell types, including endothelial cells, vascular smooth muscle cells, leukocytes, cardiomyocytes, mesangial cells, certain tumor cell lines, as well as neurons and glia in both the central and peripheral nervous systems (1-3). Local administration of ET-1 induces nociceptive behaviors in animals $(4,5)$ and causes

Correspondence to: Mr. Wenjin Ji, Department of Anesthesiology, Guangdong General Hospital, Guangdong Academy of Medical Sciences, 96 DongChun Road, Guangzhou 510080, P.R. China E-mail: jiwenjin@msn.com

Dr Zhiwei Zhang, Department of Pediatric Cardiology, Guangdong Cardiovascular Institute, Guangdong Academy of Medical Sciences, 96 DongChun Road, Guangzhou, 510080, PR China

E-mail: drzhangzhiwei@sina.com.cn

Key words: itch, к-opioid receptor, naloxone, nor-Binaltorphimine, endothelin-1 pain in humans (6). ET-1 also elicits pruritus in mice (7-9) and humans $(6,10)$. The signaling of ET-1 is mediated by two main membrane G-protein coupled receptor subtypes, $\mathrm{ET}_{\mathrm{A}}$ and $\mathrm{ET}_{\mathrm{B}}$ (11). Blockade of the $\mathrm{ET}_{\mathrm{A}}$ receptor inhibits the scratching response induced by ET-1 $(7,8,12)$, while co-injection of $\mathrm{ET}_{\mathrm{B}}$ antagonists increases scratching bouts induced by ET-1 $(8,12)$. By contrast, $\mathrm{ET}_{\mathrm{B}}$ agonists exert antipruritic effects of itch induced by both ET-1 and compound 48/80 (8).

ET-1 is secreted in response to inflammation, tissue injury and other stress stimuli. Therefore, $\mathrm{ET}_{\mathrm{B}}$ is a promising target to mitigate ET-1-induced itch symptoms. The mechanisms that drive the antipruritic effects of $\mathrm{ET}_{\mathrm{B}}$ remain to be elucidated. It has been reported that keratinocytes express $\mathrm{ET}_{\mathrm{B}}$ receptors, and upon activation may lead to the release of opium-like substances (13). Peripheral $\mu$ - and $\kappa$-opioid receptors (MORs and KORs, respectively) are reported to be involved in the antinociception effect triggered by $\mathrm{ET}_{\mathrm{B}}$ agonists $(13,14)$ Peripheral $\delta$-opioid receptors (DORs) are also considered to be involved in the antinociceptive activity of opioid peptides, which are released from neutrophils and in response to endothelin-A receptor antagonists $(15,16)$.

Peripheral MORs and KORs, but not DORs, may play key roles in pruritus $(17,18)$. For example, topical application of naltrexone inhibits pruritus in patients with atopic dermatitis (19). In addition, ICI 204448, a peripherally restricted KOR agonist, was found to antagonize chloroquine-induced scratching in mice (20). We note that neuron excitability is reduced upon opioid receptor activation, which is due to the inhibition of voltage-dependent $\mathrm{Ca}^{2+}$ channels and adenyl cyclase, as well as the activation of $\mathrm{K}^{+}$channels (21). Notably, SQ22536, a selective inhibitor of adenyl cyclase, inhibits the scratching response induced by ET-1 (12). Therefore, our goal was to investigate the effects of opioid receptor antagonists on the scratching response induced by ET-1.

\section{Materials and methods}

Animals. Male C57BL/6J mice, weighing 20-22 g, were obtained from the Center for Laboratory Animals, Sun Yat-Sen University (Guangzhou, China). The animals were housed at room temperature $\left(22 \pm 1^{\circ} \mathrm{C}\right)$ on a $12 / 12$-h light $(8$ a.m.-8 p.m.)/dark (8 p.m.-8 a.m.) cycle and had free access to rodent food and water. The experimental procedures and the animal use and care protocols 


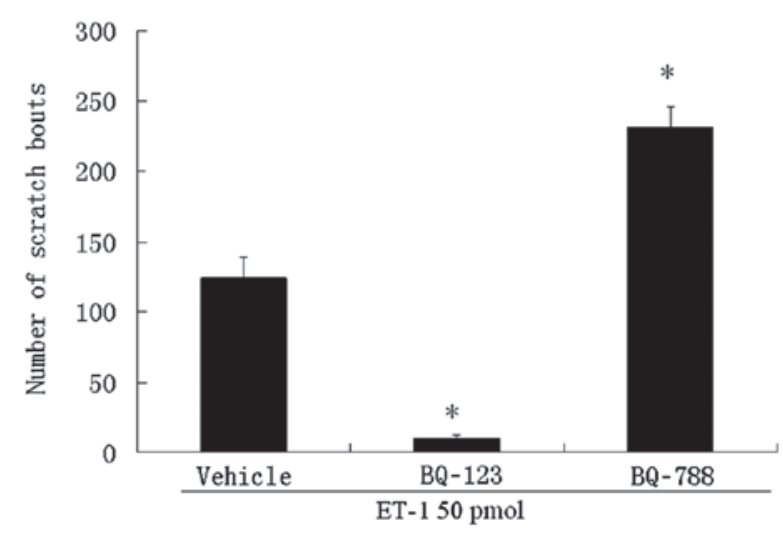

Figure 1. Effects of specific $\mathrm{ET}_{\mathrm{A}}$ and $\mathrm{ET}_{\mathrm{B}}$ receptor antagonists on the scratching response induced by ET-1. A total of 50 pmol ET-1 only, or together

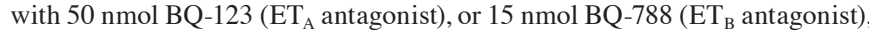
were injected intradermally $(50 \mu \mathrm{l})$. Each bar indicates the number of bouts of scratching for $30 \mathrm{~min}$ following the injection of ET-1. Data are expressed as mean \pm SEM and $n=10$ in each treatment group. ${ }^{*} \mathrm{P}<0.05$, relative to the group treated with only ET-1. ET-1, endothelin-1.

were approved by the Committee on Ethical Use of Animals of Guangdong General Hospital (Guangzhou, China). Our procedures also followed the National Institutes of Health's animal use and care guidelines. All efforts were made to minimize animal suffering and to reduce the number of animals used.

Drugs and chemicals. Synthetic ET-1, BQ-123 (ET ${ }_{\mathrm{A}}$ antagonist) and BQ-788 (ET $\mathrm{ET}_{\mathrm{B}}$ antagonist) were purchased from American Peptides (Sunnyvale, CA, USA). Naloxone hydrochloride was supplied by Kawin Technology Share-Holding Co. (Beijing, China). CTOP (Phe-Cys-Tyr-Trp-Orn-ThrPen-Thr- $\mathrm{NH}_{2}$; MOR antagonist) and nor-Binaltorphimine dihydrochloride (nor-BNI; KOR antagonist) were purchased from Sigma Chemical Co. (St. Louis, MO, USA). Naltrindole hydrochloride (DOR antagonist) was purchased from Tocris (Bristol, UK). All drugs were diluted in phosphate-buffered saline (PBS) and the $\mathrm{pH}$ was adjusted to 7.4.

Pruritus model and behavioral analysis. The pruritus model was established as previously described (12). Briefly, at one day after shaving the rostral part of the back of the neck, mice were placed into a small plastic chamber $\left(22 \times 12 \times 20 \mathrm{~cm}^{3}\right) 30 \mathrm{~min}$ prior to the experiment. For drug administration, mice were briefly removed from the chamber and $50 \mu 1$ of each test drug was intradermally injected with a 30 -gauge needle (detailed description of injection has been described elsewhere) (22). The mice were then returned to the chamber and hind limb scratching that was directed towards the shaved area at the back of the neck was observed and recorded for $30 \mathrm{~min}$. One scratch was defined as a lift of the hind limb towards the injection site and then a reposition of the limb back to the floor, regardless of the scratching strokes that took place between the two movements. All testing was conducted between 10:00 and 16:00. To reduce the injection times, antagonists or inhibitors (BQ-123 $50 \mathrm{nmol}$, BQ-788 $15 \mathrm{nmol}$, naloxone $2 \mathrm{nmol}$ or $0.5 \mathrm{mg} / \mathrm{kg}$, CTOP $10 \mathrm{nmol}$, nor-BNI $5 \mathrm{nmol}$, naltrindole $60 \mathrm{nmol}$ ) were co-injected with ET-1 (50 pmol) in a volume of $50 \mu 1$. Naloxone ( $2 \mathrm{nmol}$ or $0.5 \mathrm{mg} / \mathrm{kg}$ ) was subcutaneously injected $15 \mathrm{~min}$ prior to the administration of $50 \mu \mathrm{l} \mathrm{ET-1}(50 \mathrm{pmol})$ to investigate the role of systemic naloxone administration. The specific doses of BQ-123, BQ-788, naloxone, CTOP and naltrindole used were selected based on previous studies $(12,13,15,23)$.

Statistical analysis. Minitab 16 for windows (Minitab Inc., State College, PA, USA) was used for statistical analysis. All results are expressed as means \pm SEM. Data were statistically evaluated by analysis of variance followed by Bonferroni's test or, when only two means were to be compared, unpaired Student's t-test. $\mathrm{P}<0.05$ was considered to indicate a statistically significant result.

\section{Results}

Intradermal injections. Intradermal injections of PBS, BQ-123, BQ-788, naloxone, CTOP or naltrindole caused no noticeable scratching response. By contrast, a scratching response was elicited by intradermal injection of ET-1, or a high concentration of nor-BNI. However, there was no noticeable increment of hoarsening, grooming or paw licking with intradermal ET-1 or nor-BNI injections.

BQ-123 and ET-1 injection. Intradermal injection of $50 \mathrm{pmol}$ ET-1 evoked scratching bouts ( $124 \pm 14$ bouts). Scratching bouts induced by ET-1 were markedly inhibited when they were co-administered locally with the selective $\mathrm{ET}_{\mathrm{A}}$ receptor antagonist BQ-123 (Fig. 1). In contrast, local co-injection of the selective $\mathrm{ET}_{\mathrm{B}}$ receptor antagonist $\mathrm{BQ}-788$, substantially augmented the effect of ET-1 (231 \pm 14 bouts; Fig. 1).

Naloxone and ET-1. We then examined the effects of naloxone, an antagonist of opioid receptors, on the scratching response induced by ET-1. Pretreatment with systemically administered naloxone $0.5 \mathrm{mg} / \mathrm{kg}$ significantly reduced the number of scratches to $52 \pm 6$ compared to that induced following pretreatment with PBS (126 \pm 12 , Fig. 2A). Co-injection of naloxone $2 \mathrm{nmol}$ or $0.5 \mathrm{mg} / \mathrm{kg}$ substantially and similarly augmented the effect of ET-1 (Fig. 2B). Pretreatment with a low dose of naloxone ( $2 \mathrm{nmol})$, however, was not able to alter the scratching response (Fig. 2A). Thus, local, but not systemic naloxone, prevented the antipruritic effect induced by activation of the $\mathrm{ET}_{\mathrm{B}}$ receptor, suggesting the involvement of peripheral opioid receptors in pruritis.

CTOP, nor-BNI, naltrindole and ET-1. We also examined the effects of CTOP, nor-BNI and naltrindole (MOR, KOR and DOR antagonists, respectively) on the scratching response induced by ET-1. Intradermal injections of nor-BNI evoked dose-dependent scratching bouts (Fig. 3A). We note that $5 \mathrm{nmol}$ of nor-BNI was selected since it did not cause a noticeable scratching response. Co-injection of nor-BNI significantly increased the number of scratches (from an average of 121 to 222 bouts; Fig. 3B) induced by ET-1. CTOP and naltrindole did not alter the scratching response to ET-1 (Fig. 3B).

\section{Discussion}

In the present study, we demonstrated that the activation of peripheral endothelin B receptors exerts antipruritic effects 
A

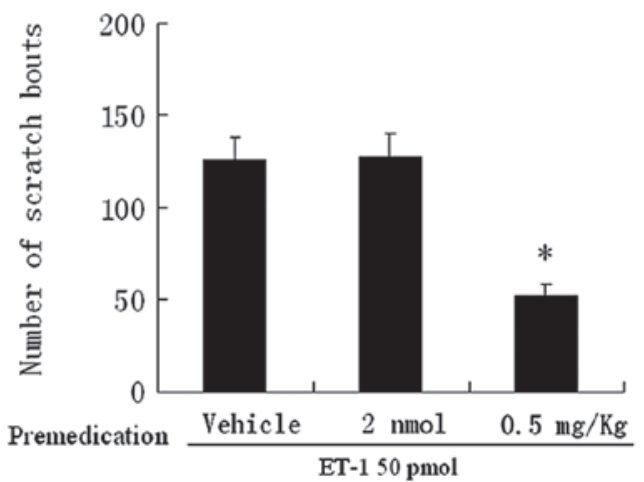

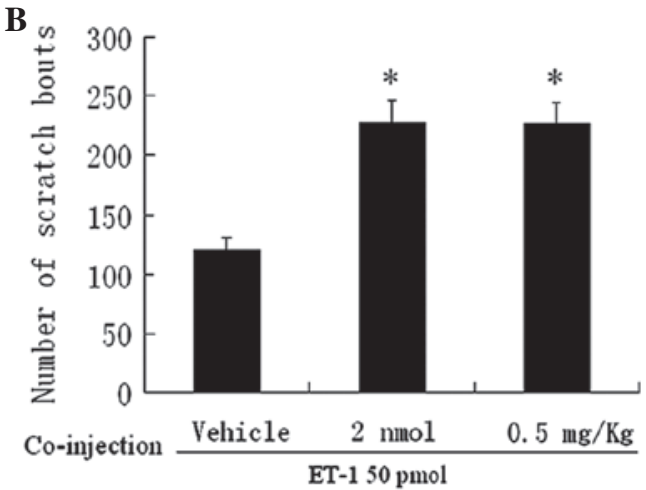

Figure 2. Effects of premedication or co-injection with naloxone on the scratching response induced by ET-1. (A) Subcutaneous naloxone ( $2 \mathrm{nmol}$ or $0.5 \mathrm{mg} / \mathrm{kg}$ ) or PBS (vehicle) was systemically injected $15 \mathrm{~min}$ prior to the administration of ET-1 (50 pmol in $50 \mu \mathrm{l}$ PBS). (B) Naloxone (2 nmol or $0.5 \mathrm{mg} / \mathrm{kg}$ ) or PBS was co-injected with ET-1 (50 pmol in $50 \mu \mathrm{l}$ PBS). Each bar indicates the scratch bouts for 30 min following the injection of ET-1. Data are expressed as mean $\pm \mathrm{SEM}$, and $\mathrm{n}=8$ in each treatment group. ${ }^{*} \mathrm{P}<0.05$ as compared with the group treated with only ET-1. ET-1, endothelin-1.

via peripheral KORs. For example, co-injection of naloxone (a non-selective opioid receptor antagonist) and nor-BNI (a KOR antagonist) with ET-1 significantly increased the number of scratches, while co-injection of CTOP (a MOR antagonist) and naltrindole (a DOR antagonist) with ET-1 did not alter the scratching response. Notably the doses of CTOP and naltrindole are sufficient to reduce the analgesic effects evoked by endogenous opioid peptides $(13,15)$.

The opioid system plays a pivotal role in modulating pruritus (18). Opioid-induced pruritus is a well-known side effect of postoperative analgesia attributed to spinal or epidural morphine, as well as administration of other MOR agonists $(24,25)$. Notably, MOR antagonists and KOR agonists have been reported to treat pruritus effectively in patients with chronic renal failure, cholestasis and atopic dermatitis (26). Opioid receptors are expressed in peripheral nerve endings and keratinocytes in human skin (27). The gastrin-releasing peptide receptor (GRPR) is an itch-specific molecule in the spinal cord (28). For example, ablation of lamina I neurons expressing GRPR in the spinal cord of mice produces profound scratching deficits in response to itching (pruritogenic) stimuli (29). Notably, GRP is co-localized with MOR in mouse skin (30). These data suggest that the opioid receptors involved in itching sensations are peripheral, as well as central (18).

Naloxone has been shown to inhibit scratching induced both by capsaicin in inflamed skin and by several pruritogens (23,31-33). It is noteworthy that co-injection with naloxone increased scratches induced by ET-1. Intradermal or subcutaneous injections of KOR antagonists induced scratching responses both in this study and in previous research (34), while intradermal injections of naloxone alone did not induce scratching, suggesting that the blockade of MORs may inhibit the pruritogenic effect of KOR antagonists.

Loperamide, a peripherally restricted MOR agonist, was also found to antagonize scratching evoked by compound 48/80 in mice (35). However, scratching responses were evoked by intradermally injected morphine, fentanyl and loperamide (36). Naloxone methiodide, a peripherally restricted opioid receptor antagonist, significantly suppressed scratching behavior induced by MOR agonists loperamide and DAMGO (37). It has also been demonstrated that $\mathrm{ET}_{\mathrm{B}}$ agonists
A
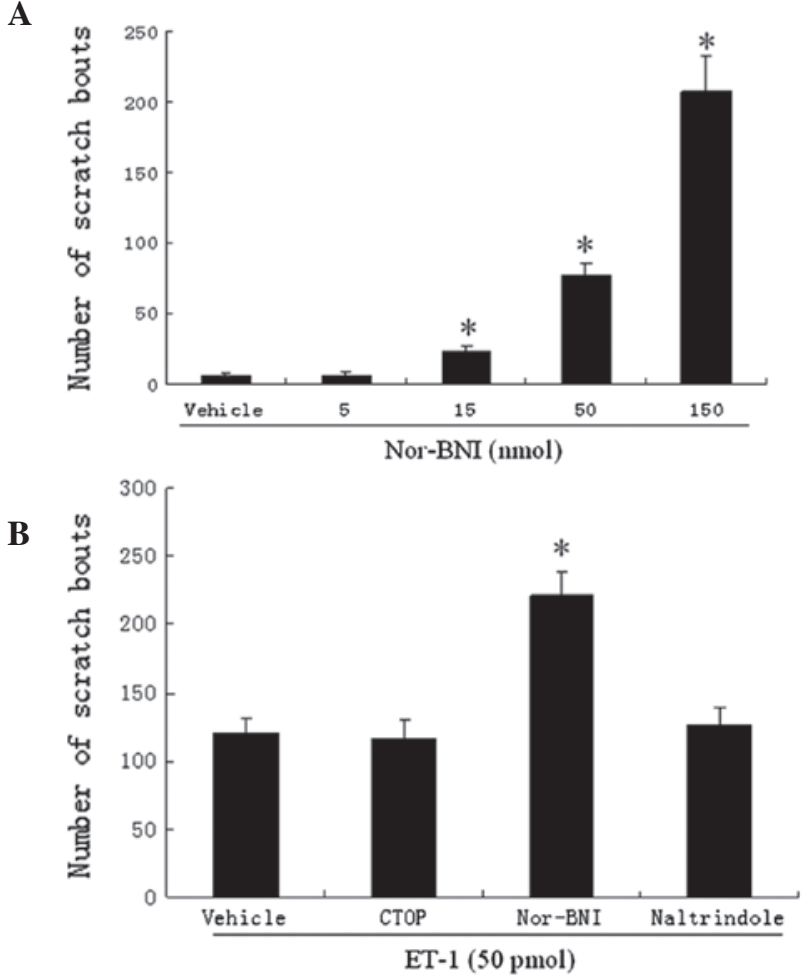

Figure 3. Pruritus induced by nor-Binaltorphimine dihydrochloride (nor-BNI) and effects of selective opioid receptor antagonists on the scratching response induced by ET-1. (A) Nor-BNI at various doses was intradermally injected in $50 \mu \mathrm{l}$ PBS. (B) CTOP $10 \mathrm{nmol}$, nor-BNI $5 \mathrm{nmol}$, naltrindole $60 \mathrm{nmol}$ or PBS was co-injected with ET-1 (50 pmol in $50 \mu 1$ PBS). Data are expressed as mean \pm SEM, and $n=8$ in each treatment group. ${ }^{*} \mathrm{P}<0.05$, as compared with the group treated with vehicle. ET-1, endothelin-1.

injected into the neck induced scratching in female BALB/C mice (7), while no scratching response was induced in male Swiss mice (8). By contrast, $\mathrm{ET}_{\mathrm{B}}$ antagonists injected into the neck induced scratching in male Swiss mice (8), while it did not induce scratching in this study, as well as previous studies using male C57BL/6J mice (12). CTOP was not able to inhibit the scratching response induced by ET-1 in the current study, indicating the significance of genetic backgrounds in determining puritogenic sensitivity to peripheral MOR agonists. 
Activation of neuronal KORs reduces neuronal excitability via various pathways (21). However, it is possible to exert antipruritic effects via non-neuronal pathways. For example, we recently observed that activation of transient receptor potential ankyrin subfamily member 1 (TRPA1) suppresses itch responses induced by ET-1 (38). Notably, TRPA1 and KORs are expressed in human keratinocytes $(39,40)$. It will be valuable to evaluate the role of TRPA1 and KORs in keratinocytes.

In summary, we investigated the involvement of peripheral opioid receptors in ET-1-induced pruritus in mice. We suggest that peripheral KORs mediate the antipruritic effects of endothelin $\mathrm{B}$ receptor activation.

\section{Acknowledgements}

This study was supported by the National Natural Science Foundation (Nos. 30872437 and 81171040), Natural Science Foundation of Guangdong Province (No. 8151008004000017) and Science and Technology Project of Guangdong Province (2011), China.

\section{References}

1. Hans G, Deseure K and Adriaensen H: Endothelin-1-induced pain and hyperalgesia: a review of pathophysiology, clinical manifestations and future therapeutic options. Neuropeptides 42 : 119-132, 2008

2. Giaid A, Gibson SJ, Ibrahim BN, Legon S, Bloom SR, Yanagisawa M, Masaki T, Varndell IM and Polak JM: Endothelin 1, an endothelium-derived peptide, is expressed in neurons of the human spinal cord and dorsal root ganglia. Proc Natl Acad Sci USA 86: 7634-7638, 1989.

3. MacCumber MW, Ross CA and Snyder SH: Endothelin in brain: receptors, mitogenesis, and biosynthesis in glial cells. Proc Natl Acad Sci USA 87: 2359-2363, 1990.

4. Piovezan AP, D'Orleans-Juste P, Souza GE and Rae GA: Endothelin-1-induced ETA receptor-mediated nociception, hyperalgesia and oedema in the mouse hind-paw: modulation by simultaneous ETB receptor activation. Br J Pharmacol 129: 961-968, 2000.

5. Gokin AP, Fareed MU, Pan HL, Hans G, Strichartz GR and Davar G: Local injection of endothelin-1 produces pain-like behavior and excitation of nociceptors in rats. J Neurosci 21: 5358-5366, 2001.

6. Hans G, Deseure K, Robert D and De Hert S: Neurosensory changes in a human model of endothelin-1 induced pain: a behavioral study. Neurosci Lett 418: 117-121, 2007.

7. McQueen DS, Noble MA and Bond SM: Endothelin-1 activates ETA receptors to cause reflex scratching in BALB/c mice. Br J Pharmacol 151: 278-284, 2007.

8. Trentin PG, Fernandes MB, D'Orleans-Juste P and Rae GA: Endothelin-1 causes pruritus in mice. Exp Biol Med (Maywood) 231: 1146-1151, 2006.

9. Imamachi N, Park GH, Lee H, Anderson DJ, Simon MI, Basbaum AI and Han SK: TRPV1-expressing primary afferents generate behavioral responses to pruritogens via multiple mechanisms. Proc Natl Acad Sci USA 106: 11330-11335, 2009.

10. Katugampola R, Church MK and Clough GF: The neurogenic vasodilator response to endothelin-1: a study in human skin in vivo. Exp Physiol 85: 839-846, 2000.

11. Lipa JE, Neligan PC, Perreault TM, Baribeau J, Levine RH, Knowlton RJ and Pang CY: Vasoconstrictor effect of endothelin-1 in human skin: role of ETA and ETB receptors. Am J Physiol 276: H359-H367, 1999.

12. Liang J, Kawamata T and Ji W: Molecular signaling of pruritus induced by endothelin-1 in mice. Exp Biol Med (Maywood) 235: 1300-1305, 2010.

13. Khodorova A, Navarro B, Jouaville LS, et al: Endothelin-B receptor activation triggers an endogenous analgesic cascade at sites of peripheral injury. Nat Med 9: 1055-1061, 2003.
14. Quang PN and Schmidt BL: Peripheral endothelin B receptor agonist-induced antinociception involves endogenous opioids in mice. Pain 149: 254-262, 2010.

15. Rittner HL, Hackel D, Voigt P, Mousa S, Stolz A, Labuz D, Schäfer M, Schaefer M, Stein C and Brack A: Mycobacteria attenuate nociceptive responses by formyl peptide receptor triggered opioid peptide release from neutrophils. PLoS Pathog 5: e1000362, 2009.

16. Quang PN and Schmidt BL: Endothelin-A receptor antagonism attenuates carcinoma-induced pain through opioids in mice. $\mathrm{J}$ Pain 11: 663-671, 2010.

17. Ikoma A, Steinhoff M, Ständer S, Yosipovitch G and Schmelz M: The neurobiology of itch. Nat Rev Neurosci 7: 535-547, 2006.

18. Tominaga $\mathrm{M}$ and Takamori $\mathrm{K}$ : Recent advances in pathophysiological mechanisms of itch. Expert Rev Dermatol 5: 197-212, 2010.

19. Bigliardi PL, Stammer H, Jost G, Rufli T, Büchner S and Bigliardi-Qi M: Treatment of pruritus with topically applied opiate receptor antagonist. J Am Acad Dermatol 56: 979-988, 2007.

20. Inan $S$ and Cowan A: Kappa opioid agonists suppress chloroquine-induced scratching in mice. Eur J Pharmacol 502: 233-237, 2004.

21. Satoh M and Minami M: Molecular pharmacology of the opioid receptors. Pharmacol Ther 68: 343-364, 1995.

22. Shimada SG and LaMotte RH: Behavioral differentiation between itch and pain in mouse. Pain 139: 681-687, 2008.

23. Liang J, Xiao G and Ji W: Capsaicin induces reflex scratching in inflamed skin. Pharmacology 88: 82-87, 2011.

24. Ballantyne JC, Loach AB and Carr DB: Itching after epidural and spinal opiates. Pain 33: 149-160, 1988.

25. Cousins MJ and Mather LE: Intrathecal and epidural administration of opioids. Anesthesiology 61: 276-310, 1984.

26. Bigliardi PL, Tobin DJ, Gaveriaux-Ruff $C$ and Bigliardi-Qi M: Opioids and the skin - where do we stand? Exp Dermatol 18: 424-430, 2009.

27. Bigliardi-Qi M, Sumanovski LT, Büchner S, Rufli T and Bigliardi PL: Mu-opiate receptor and beta-endorphin expression in nerve endings and keratinocytes in human skin. Dermatology 209: 183-189, 2004.

28. Sun YG and Chen ZF: A gastrin-releasing peptide receptor mediates the itch sensation in the spinal cord. Nature 448: 700-703, 2007.

29. Sun YG, Zhao ZQ, Meng XL, Yin J, Liu XY and Chen ZF: Cellular basis of itch sensation. Science 325: 1531-1534, 2009.

30. Tominaga M, Ogawa $\mathrm{H}$ and Takamori K: Histological characterization of cutaneous nerve fibers containing gastrin-releasing peptide in NC/Nga mice: an atopic dermatitis model. J Invest Dermatol 129: 2901-2905, 2009.

31. Andoh T, Nagasawa T, Satoh $M$ and Kuraishi Y: Substance P induction of itch-associated response mediated by cutaneous NK1 tachykinin receptors in mice. J Pharmacol Exp Ther 286: 1140-1145, 1998.

32. Andoh T, Yageta Y, Takeshima H and Kuraishi Y: Intradermal nociceptin elicits itch-associated responses through leukotriene B(4) in mice. J Invest Dermatol 123: 196-201, 2004.

33. Yamaguchi T, Nagasawa T, Satoh M and Kuraishi Y: Itch-associated response induced by intradermal serotonin through 5-HT2 receptors in mice. Neurosci Res 35: 77-83, 1999.

34. Kamei J and Nagase H: Norbinaltorphimine, a selective $\kappa$-opioid receptor antagonist, induces an itch-associated response in mice. Eur J Pharmacol 418: 141-145, 2001.

35. DeHaven-Hudkins DL, Cowan A, Cortes Burgos L, Daubert JD, Cassel JA, DeHaven RN, Kehner GB and Kumar V: Antipruritic and antihyperalgesic actions of loperamide and analogs. Life Sci 71: 2787-2796 2002 .

36. Yamamoto A, Kuyama S, Kamei C and Sugimoto Y: Characterization of scratching behavior induced by intradermal administration of morphine and fentanyl in mice. Eur J Pharmacol 627: 162-166, 2010.

37. Yamamoto A and Sugimoto Y: Involvement of peripheral mu opioid receptors in scratching behavior in mice. Eur J Pharmacol 649: 336-341, 2010.

38. Liang J, Ji Q and Ji W: Role of transient receptor potential ankyrin subfamily member 1 in pruritus induced by endothelin-1. Neurosci Lett 492: 175-178, 2011.

39. Tominaga M, Ogawa $\mathrm{H}$ and Takamori K: Possible roles of epidermal opioid systems in pruritus of atopic dermatitis. J Invest Dermatol 127: 2228-2235, 2007.

40. Atoyan R, Shander D and Botchkareva NV: Non-neuronal expression of transient receptor potential type A1 (TRPA1) in human skin. J Invest Dermatol 129: 2312-2315, 2009. 